\title{
As Exportações Brasileiras por Grau de Elaboração entre 1980 \\ e 2015: Aplicação do Modelo Eaton-Kortum à luz da Teoria \\ Cepalina
}

\section{Brazilians' Exports by Degree of Elaboration between 1980 to 2015: Eaton-Kortum's Model Application Based on the ECLAC Theory}

\author{
Édivo de Almeira Oliveira" \\ William Barbosa** \\ Júlio Vicente Cateia*** \\ Paulo Ricardo Feistel ${ }^{* * * *}$
}

\begin{abstract}
Resumo: Este trabalho tem como objetivo analisar empiricamente as exportações brasileiras por grau de elaboração entre 1980 e 2015 à luz da teoria cepalina, articulando-a com o modelo gravitacional Eaton-Kortum - que tem se destacado pela incorporação de elementos estruturais em sua análise. Os resultados obtidos indicam que tanto para o modelo gravitacional considerado, quanto para a teoria estruturalistacepalina o preço relativo, o tamanho das economias e as barreiras comerciais emergem como parâmetros que expressam o fluxo e a qualidade das trocas realizadas entre as economias. A análise econométrica comprova a importância do PIB, bem como da técnica e das barreiras comerciais na explicação das exportações brasileiras por grau de elaboração. Porém, os resultados sugerem pouca efetividade dos preços relativos em fomentar as vendas externas nacionais.
\end{abstract}

Palavras-chave: Exportações. Modelo Eaton-Kortum. Teoria cepalina.

\begin{abstract}
The goal of this work is to analyze empirically the Brazilian exports by degree of elaboration between 1980 and 2015 based on the ECLAC theory, articulating it with the gravitational model Eaton-Kortum - that has been distinguished by the incorporation of structural elements in its analysis. The results obtained indicate that relative price, size of economies and trade barriers emerge as parameters for the considered gravitational model, as well as for structuralist-ECLAC theory, as parameters that express the flow and the quality of exchanges among economies. Econometric analysis proves the importance of GDP, as well as technical and trade barriers in the explanation of Brazilian exports by degree of elaboration. However, the results suggest little effectiveness of relative prices in fostering domestic foreign sales.

* $\quad$ Doutorando em Economia pela Universidade Estadual de Campinas (Unicamp). E-mail: edivokin@hotmail.com

** Doutorando em Economia Aplicada pela Universidade de São Paulo (USP). E-mail: william_ barbosa00@hotmail.com

*** Doutorando em Economia pela Universidade Federal do Paraná (UFPR). E-mail: juliocateia@ yahoo.com.br

**** Doutor em Economia pela Universidade Federal de Pernambuco (UFPE). Professor no Programa de Pós-Graduação em Economia e Desenvolvimento da Universidade Federal de Santa Maria (UFSM). E-mail: prfeistel@yahool.com.br
\end{abstract}


Keywords: Exports. Eaton-Kortum's Model. ECLAC Theory.

JEL Classification: O24; R19; O24.

\section{Introdução}

O comércio internacional tem sido alvo de uma grande evolução teórica, com vistas a investigar os fatores causais que sustentam a dinâmica das trocas entre regiões distintas. Tais argumentos podem incorporar elementos de cunho mais crítico ou, alternativamente, guardar maior proximidade com as prerrogativas defendidas pelo establishment acadêmico vigente. Por outro lado, essas análises também podem ser fundadas em métodos mais quantitativos ou ser basicamente de uma linha mais teórico-analítica, em que grande importância é atribuída à investigação histórica.

Embora essas abordagens sejam bastante distintas, contêm certas proposições e diagnósticos acerca da forma e das consequências concernentes à inserção das economias no âmbito do comércio internacional que ao mesmo tempo convergem e se distanciam. Dentre essas teorias destacam-se: a) a teoria estruturalista-cepalina e; b) os modelos gravitacionais de comércio internacional. As diferenças entre essas abordagens não são triviais. No entanto, um modelo recente e bastante promissor dentre aqueles da linha gravitacional parece abrir um canal de diálogo com a teoria estruturalista; e a investigação do potencial dessa comunicação conceitual-metodológica faz todo o sentido, uma vez que o modelo de Eaton e Kortum (2002) busca incorporar elementos ditos estruturais em sua análise.

Isso pode ser visto em algumas assertivas teóricas pertinentes ao modelo de Eaton e Kortum (2002) que se relacionam com as proposições cepalinas. Tanto na teoria cepalina quanto no modelo de Eaton e Kortum (2002) existe convergência, ao demonstrarem uma explícita preocupação com a necessidade de avançar-se em relação às questões estruturais que norteiam o comportamento das economias, notadamente, em termos de qualidade e desempenho no comércio internacional. Em ambas, há o reconhecimento de que existem fatores causais que permitem explicar a qualidade das relações comerciais estabelecidas entre economias, dadas as suas diferentes capacidades competitivas. Portanto, o esforço de Eaton e Kortum (2002) em avançar numa análise estrutural levanta a questão acerca de possíveis áreas de tangências e de viabilidade do eventual emprego desse ferramental também em análises estruturalistas.

A análise original de Eaton e Kortum (2002) demonstra a validade de uma relação negativa entre o fluxo de comércio e os diferenciais de preços (preços relativos) entre as diferentes economias europeias, bem como o fato de que o enfraquecimento das vantagens comparativas nas trocas comerciais entre essas nações resulta no aumento da elasticidade das importações em relação aos preços 
relativos e às barreiras geográficas. Pico Bonilla (2011) replica o estudo desses autores com o intuito de avaliar o impacto do processo de liberalização do comércio internacional nos setores manufaturados para os países latino-americanos e infere que a relação negativa entre o fluxo de comércio e os preços relativos pode ser considerada válida para os países da região, embora de maneira menos contundente do que na Europa. Ainda nesse trabalho, Pico Bonilla (2011) elucida que os países da América Latina são mais heterogêneos e dependentes das vantagens comparativas do que os países europeus.

Esses estudos corroboram os argumentos já enunciados por Prebisch (2000) e Furtado (1992) ao demonstrarem a importância das análises estruturais no processo de diagnóstico dos principais problemas observados nas economias latino-americanas - a exemplo do Brasil, em que parte significativa de sua história econômica baseou-se na dinâmica de setores primário-exportadores dotados de baixa capacidade de difusão do progresso técnico, com baixa produtividade em relação ao setor industrial. Tal processo engendrou uma dinâmica, no âmbito do comércio internacional, desfavorável à superação do atraso técnico e social que caracteriza essas economias.

Um exercício analítico das exportações brasileiras a partir dessas proposições cepalinas, associadas com o método de Eaton-Kortum, será esboçado ao longo do presente trabalho, sendo aplicado para as exportações de bens de capital, intermediários, consumo duráveis e não duráveis entre 1980 e 2015. A problemática que norteia o presente trabalho é: quais são os pontos de tangência e divergência teórica entre a teoria cepalina e o modelo de Eaton e Kortum (2002) e como utilizá-los na compreensão das exportações brasileiras por grau de elaboração? Para tanto, em um primeiro momento serão expostos e avaliados os pontos de tangência e discrepância entre ambos, sucedidos pela aplicação do modelo de Eaton-Kortum para as exportações brasileiras, cuja interpretação dos resultados é balizada por algumas proposições defendidas pelos teóricos cepalinos.

Além desta introdução, o presente trabalho é composto da seguinte forma: a segunda seção explana e compara as teorias consideradas; a terceira seção apresenta a metodologia utilizada para a aplicação do modelo Eaton e Kortum (2002) para o caso das exportações brasileiras; a quarta seção realiza a análise dos resultados obtidos; e, por fim, a quinta seção traça as considerações finais.

\section{A Teoria Cepalina e o Modelo de Eaton-Kortum}

A teórica estruturalista-cepalina sustentava como objetivo a identificação dos entraves estruturais concernentes ao processo de diferenciação produtiva da região latino-americana e à inserção dessa região de maneira mais qualificada no âmbito do comércio internacional. O Modelo de Eaton-Kortum também busca a 
apreensão dos problemas estruturais sob uma perspectiva estrutural, no escopo de um modelo econométrico de matiz gravitacional mais geral. Em que pese as substanciais diferenças entre essas abordagens, alguns canais de convergência teórica são possíveis de serem identificadas. Senão, vejamos.

\subsection{Breve Consideração da Teoria Estruturalista-Cepalina}

As contribuições cepalinas ocorreram em um período histórico muito importante que levou os economistas latino-americanos a afirmarem que, a despeito da validade teórica da divisão internacional do trabalho ser incontestável, o caráter geral que lhe atribuem consiste em algo bastante circunscrito aos países industrializados (PREBISCH, 2000). Com efeito, o establishment neoclássico, baseado nas vantagens comparativas ricardianas, defendia que, mediante o comércio internacional, os países primário-exportadores participariam dos frutos do progresso técnico ocorrido nos países industrializados, seja pelo aumento da renda, seja pela queda nos preços relativos dos produtos manufaturados. No entanto, para Prebisch (2000), esse processo fora validado somente pelas realidades factuais daquelas economias já industrializadas, cujo progresso técnico elevou a produtividade e aumentou a parcela da renda direcionada à poupança e, consequentemente, viabilizou a realização de novas inversões em seus mercados.

O fato desse progresso técnico não ter alcançado a periferia, inviabilizando o alcance de maiores níveis de produtividade, teria comprometido sua capacidade de estabelecer os níveis necessários de poupança para o seu desenvolvimento, o que explicaria as graves e grandes diferenças entre o padrão de vida apresentado pela população do centro e da periferia da economia mundial. Entre os fatores que explicam essa discrepância, que se torna mais evidente em período de oscilações econômicas, ressaltam-se os preços relativos. Um reexame dos dados do comércio convenceu Prebisch (2000) que, em período de crise, os preços dos produtos manufaturados não caíam na mesma velocidade e magnitude que a queda dos preços dos produtos primários de baixo valor. Isso porque, embora se verificasse uma redução dos custos em função do aumento da produtividade decorrente do progresso técnico, a elevação da renda dos fatores de produção acima da produtividade implicava uma sensível pressão de alta sobre os preços no centro, fenômeno diametralmente oposto ao que ocorrera na periferia.

A teoria dos termos de troca se baseava na crítica feita ao argumento sustentado pelo mainstream vigente. Este afirmava que os efeitos da especialização e do progresso técnico seriam benéficos não somente aos países exportadores de produtos manufaturados, mas também aos demais países, inclusive aos primário-exportadores, dado que estes usufruiriam dos resultados desse processo na medida 
em que tal fenômeno implicasse a queda dos preços dos produtos manufaturados no comércio internacional ou a elevação da renda (OLIVEIRA; SANTOS, 2008).

A partir dessa constatação, Prebisch (2000, p. 83) explicita uma inferência hoje clássica para os corolários de suas ideias, a saber: "[...] enquanto os centros preservaram integralmente o fruto do progresso técnico de sua indústria, os países periféricos transferiram para eles uma parte do fruto do seu próprio progresso técnico [...]". Um dos expoentes do pensamento cepalino, Celso Furtado (1992), traduz a intrínseca relação entre produtividade e progresso técnico ao explicar que:

Já se vão quarenta anos desde que Prebisch nos ensinou a observar o capitalismo como um processo de difusão do progresso técnico, difusão irregular, comandada pelos interesses das economias criadoras de novas técnicas. Quem diz progresso técnico diz aumento de produtividade, portanto condições propícias à concentração dinâmica da renda e impulso à acumulação, vetor da difusão de novas técnicas. (FURTADO, 1992, p. 5).

Prebisch (2000) também defendeu as inversões de capital no setor secundário das economias periféricas a fim de aumentar sua produtividade e oportunizar maiores níveis de capacidade de capitalização. $\mathrm{O}$ incremento líquido da produtividade, mutatis mutandis, seria viabilizado mediante a incorporação do progresso técnico no setor primário e, mais importante ainda, no setor industrial, o que levaria a um aumento dos postos de trabalho, bem como a acréscimos no nível de renda per capita e, por conseguinte, a maiores níveis de poupança. Por trás dessas assertivas se encontra a noção de que a produção primário-exportadora é intrinsecamente restrita quanto a sua capacidade de incorporar valor agregado e dinamizar as economias periféricas, por conta do atraso técnico que lhes caracterizam. Portanto, como solução, o autor enunciava a elevação do nível de capital per capita, sobretudo, nas atividades industriais, por intermédio da intensificação da acumulação e racionalização do capital, que engendraria um aumento da produtividade dessas economias e, por conseguinte, geraria incrementos na renda nacional e no nível de poupança, de modo que as novas inversões de capital quebrasse o círculo vicioso de atraso técnico-produtivo no qual estavam presos, catalisando uma série de mudanças sociais positivas.

Isso posto, o intercâmbio comercial puramente coordenado pelo livre mercado baseado na divisão internacional do trabalho estabelecida a per se não seria suficiente para garantir que as economias primário-exportadoras usufruíssem dos benefícios que só o progresso técnico é capaz de gerar em uma sociedade. A Cepal (COMISSÃO ECONÔMICA PARA AMÉRICA LATINA E CARIBE, 2000) defendia a tese de que a transferência de parcela dos benefícios do progresso técnico da periferia para o centro se processou em função das transformações dinâmicas que 
ocorreram no cenário econômico mundial, da escassa mobilidade dos fatores de produção e da lentidão das atividades produtivas.

A discrepância entre os raciocínios teóricos, baseados na mobi-
lidade absoluta dos fatores produtivos, e os fenômenos reais da
economia tem um significado tão grande para a teoria do de-
senvolvimento econômico da América Latina, em especial, e
de toda a periferia, em geral, que se impõe um sério esforço de
revisão teórica, o qual, partindo de premissas mais compatíveis
com a realidade, possa ajudar-nos a formular em bases sólidas as
linhas essenciais de uma política de desenvolvimento econômi-
ca. (COMISSÃ̂..., 2000, p. 157).

Nesse panorama, as distintas formas de inserção das economias na divisão internacional do trabalho imprimem certas características estruturais às economias componentes da periferia mundial, que se traduzem em uma elasticidade-renda das importações superior à elasticidade-renda da demanda por exportações. Essa disfunção reside no fato de que a periferia demanda produtos e bens de alto valor agregado do centro à medida que experimenta novas evoluções técnicas e reduz relativamente sua demanda por matérias-primas e insumos produzidos nos países primário-exportadores (PORCILE; ESTEVES; SCATOLIN, 2006).

Prebisch (2000) entende a industrialização como uma condição sine qua non para que, mediante incremento da produtividade, a periferia possa se proteger contra a vulnerabilidade externa e manter parte dos frutos do progresso técnico direcionados para o centro, além de reverter o modo de sua inserção na divisão internacional do trabalho estruturalmente "inglória" e perversa ao seu próprio desenvolvimento, já que os investimentos implicam em indelével aumento da produtividade do trabalho, que repercute positivamente nos níveis de poupança e nas possibilidades de manutenção desse ciclo virtuoso de desenvolvimento. Nesse sentido, evidencia-se que, para o economista argentino, a qualidade e o padrão técnico-produtivo de cada economia definem em grande medida a sua forma de inserção no âmbito do comércio internacional e na distribuição dos benefícios do progresso técnico, de modo que em última instância também são responsáveis pela dinâmica de crescimento ou desenvolvimento predominante em cada sociedade. ${ }^{1}$

$1 \quad$ Argumento esse já enunciado anteriormente na pioneira teoria de desenvolvimento formulada por Schumpeter (1982), em que a inovação seria a estratégia mais utilizada pelas firmas no enfretamento concorrencial, sendo a abertura de novos mercados uma das formas de manifestação da própria atividade inovativa. Tal proposição foi melhor desenvolvida pelos neoschumpeterianos, dentre os quais Dosi (1982), ao afirmar que distintos produtos apresentam trajetórias tecnológicas diferentes, dado as distintas percepções de oportunidades de mercado que cada um deles engendram no seu processo de evolução tecnológica. Sobre isso, Freeman e Perez (1988) complementam que mudanças no paradigma tecno-econômico estabelecem novas tendências de inovações radicais e incrementais que induzem novos padrões de investimentos à medida que: a) redefine as estruturas de custos relativos das empresas; b) abre novos mercados; e c) amplia as 
O aumento da produtividade advinda do progresso técnico não só se traduz em um aumento da produção nos setores menos produtivos, mas também num processo em que se desenvolve um deslocamento da mão de obra empregada improdutivamente de trabalhadores para as atividades com maior produção per capita (PREBISCH, 2000). Com os desdobramentos positivos dos fenômenos avultados, o próprio surgimento de novos postos de trabalho atenuaria a redução do nível de emprego nos setores mais atrasados em função da evasão dos investimentos. Esse é o quadro geral pelo qual o progresso técnico melhoraria o padrão de vida dos cidadãos pertencentes as mais diversas classes sociais em uma dada economia para os autores dessa tradição teórica.

$\mathrm{Na}$ abordagem cepalina, a produtividade está fortemente associada à própria noção de desenvolvimento concebida pelos seus adeptos, uma vez que o aumento da produtividade seria uma condição inalienável e imprescindível caso o objetivo de uma economia fosse se desenvolver. Portanto, os países periféricos deveriam aumentar a relação capital-produto e se esforçar para promover a diferenciação de suas economias, almejando maiores níveis de produtividade, e elevar a renda per capita, gerando maiores patamares de poupança, que, por sua vez, viabilizaria novos investimentos e novas oportunidades de ampliação da produtividade em um ciclo virtuoso de desenvolvimento.

Tavares (1975), em uma análise retrospectiva, argumenta que a industrialização dos países periféricos com base na substituição das importações se daria a partir de dois estágios, e que não necessariamente deveriam ser realizados em momentos distintos, e admitia que a primeira fase seria convenientemente o passo inicial para que os países periféricos viabilizassem sua industrialização, a saber: a) no primeiro estágio, se estabeleceria a produção doméstica de bens de consumo final, dado a sua menor exigência de densidade de capital, tecnologia e complexidade, bem como pelo amplo mercado interno brasileiro para esses produtos; b) o segundo e mais complicado estágio seria a produção de bens intermediários e de capital como condição para o aprofundamento da cadeia produtiva nacional e a diversificação de sua plataforma industrial.

\subsection{Modelo Eaton-Kortum}

O presente estudo trabalha com uma versão do modelo de equilíbrio geral, o modelo de Jonathan Eaton e Samuel Kortum (2002), derivado do modelo gravitacional, com a particularidade de ser multibens, amplamente discutido por Baldwin e Harrigan (2011). O modelo Eaton-Kortum (EK) é um modelo ricardiano multipaís que considera os custos relacionados às trocas comerciais. Diferentemente

oportunidades de investimentos dos mercados existentes associados à inovação. 
dos modelos de gravidade macroeconômicas, nos quais a competição pode se dar tanto na origem quanto no destino dos produtos, nesse modelo o locus da competição entre as nações exportadoras é único e concentra-se exatamente na nação de destino, cujas condições de concorrência dos produtos devem ser atendidas pelas nações exportadoras.

A intuição fundamental do modelo Eaton-Kortum é a de que existem várias nações que competem entre si com base nos preços dos custos, seguros e fretes (CIF). As nações demandantes pesquisam os preços cobrados por esses bens em diferentes mercados exportadores, com o intento de comprá-los a preços inferiores. Assim, o comércio de qualquer produto depende dessa atribuição de preços, sujeita aos custos de transporte e outros fatores que dificultam a fluidez do comércio. A nação com preço menor captura todo o mercado e passa a comportar-se como monopolista, o que restringe os países demandantes a um único fornecedor. A competitividade dos produtos de um país em um determinado mercado depende primordialmente da tecnologia do país exportador, do salário e dos custos de comércio bilateral em relação aos custos dos seus concorrentes. Os ganhos do comércio são maiores quanto maior for a variação das produtividades individuais, que consiste no parâmetro-chave do modelo (ALVAREZ; LUCAS JUNIOR, 2007).

Em função dessa estrutura básica, o modelo considera que as nações altamente competitivas exportam uma maior gama de mercadorias, quando em cotejo com as nações menos competitivas. A intuição é de que produtos de custo mais alto são menos propensos a serem enviados a distâncias mais longas e para mercados mais remotos. Como consequência desse efeito-composição, o preço médio de exportação diminuirá com a distância, aumentando em afastamento, e não em relação ao seu tamanho (BALDWIN; HARRIGAN, 2011, p. 67). Conforme Baldwin e Harrigan (2011, p. 63), a principal novidade do modelo Eaton-Kortum é a importância que descreve a tecnologia de cada nação. Nesse modelo, o vetor de cada nação dos coeficientes de insumo unitário de trabalho não é explicitamente especificado, mas assumido como um resultado de um processo de geração estocástica.

Com o ambiente de concorrência perfeita para representar uma probabilidade de que uma nação tenha uma vantagem comparativa, em um determinado mercado do bem tipicamente produzido nesse país, identifica-se a relação entre a nação produtora com unidades de trabalho requeridas para produzir esse bem, da seguinte forma:

$$
\left.F_{0}(a)=1-e_{-}^{T_{0} a \theta}\right), T_{0}, a \geq 0 \quad \text { e } \theta>1, \text { e } 0=1, \ldots ., C .
$$

em que $\mathrm{F}_{0}$ é a nação produtora do bem comercializável; $\mathrm{a}_{0}(\mathrm{j})$ é o coeficiente unitário de trabalho, independente da função distribuição cumulativa, requerido para 
produzir um bem local $j$; $T_{0}$ é o parâmetro específico da nação, que reflete a sua vantagem absoluta; e $C$ é o número de nações. A nação-origem, ou exportadora, ofertará um bem $j$ no mercado da nação importadora a um determinado preço, representado da seguinte forma:

$$
P_{\text {od }}(j)=\tau_{\text {od }} W_{0} a_{0}
$$

em que $\mathrm{W}_{0}$ é o salário da nação-exportadora. Em equilíbrio, os preços no mercado serão distribuídos assim:

$$
\mathrm{G}_{\mathrm{d}}(\mathrm{p})=1-\exp \left[-\Delta_{\mathrm{d}} \mathrm{p}^{\Theta}\right], \Delta_{\mathrm{d}} \equiv \sum_{c=1}^{c} \mathrm{~T}_{\mathrm{cd}}, \mathrm{T}_{\mathrm{cd}} \equiv \mathrm{T}_{\mathrm{c}} /\left(\mathrm{W}_{\mathrm{c}} \tau_{\mathrm{cd}}\right)^{\Theta}
$$

A distribuição espacial de preços de importação, ou seja, a distribuição de preços dentro da nação de destino, é dada pela equação 2, dado que cada nação exportadora tem uma probabilidade de ser o fornecedor de um determinado bem. A média do preço do CIF dos bens importados de cada parceiro deve ser idêntica e relacionada ao índice de preços da nação de destino, dado por:

$$
\mathrm{P}_{\mathrm{od}}^{\mathrm{e}}=(\Gamma[(1-\sigma+\theta) / \theta] / \Gamma[(1+\theta) / \theta])
$$

em que $\Gamma$ [·] é a função gama. Como os custos de comércio são integralmente repassados sob concorrência perfeita, a média do preço de comércio bilateral da $\mathrm{FOB}, \mathrm{P}^{\mathrm{e}}{ }_{\mathrm{od}} / \tau_{\mathrm{od}}$, deve ser o aumento do índice de preços do país de destino (afastamento) em declínio ao se considerar a distância bilateral. Dado as três equações anteriores, então a probabilidade da nação de origem ter uma vantagem comparativa no mercado da nação de destino para qualquer bem exportado é dada por:

$$
\pi_{\text {od }}=\mathrm{T}_{\text {od }} / \sum_{c=1}^{c} \mathrm{~T}_{\text {cd }},=\mathrm{T}_{\text {od }} / \Delta_{\mathrm{d}}
$$

em que $\mathrm{T}_{\text {od }}$ é inversamente relacionada ao custo unitário médio de mão de obra requerida para produzir os bens entregues no mercado. Portanto, a probabilidade de observar o fluxo positivo de comércio entre as nações em um determinado bem, $\pi_{\text {od }}$, representa a relação comparativa entre os custos unitários de trabalho médio da nação exportadora e os de seus concorrentes no mercado externo.

Baldwin e Harrigan (2011) comentam que o modelo Eaton-Kortum não produz soluções para os salários de equilíbrio, de modo que não há uma solução fechada para . No entanto, para esses autores, é possível vincular $\mathrm{T}_{\text {od }} \mathrm{s}$ às variáveis observáveis, simplesmente empregando as condições de equilíbrio de mercado para todas as nações. Isto é, uma condição em que os salários se ajustam para permitir que todas as produções das nações sejam vendidas. Disso segue que: 


$$
\pi_{0 d}=Y_{0}\left(\frac{P_{d}}{\tau_{o d}}\right)^{\Theta}\left(\frac{1}{Y_{0} P_{d}{ }^{\theta}+\Sigma_{c \neq d} Y_{c}\left(\frac{P_{c}}{\tau_{o c}}\right)^{\theta}}\right)
$$

de modo que $\mathrm{Y}_{0}$ é a produção total (PIB) das nações; $\mathrm{P}_{d}$ e $\mathrm{P}_{\mathrm{c}}$ são os índices de preços das nações, a partir da equação 1 , para bens contínuos $\Theta=[0,1]$. A distância está correlacionada com o comércio, de modo que o fluxo de exportações declina com a distância. Como os custos médios mais altos na nação de destino tende a elevar os preços locais, o custo de comércio bilateral também aumenta, desde que os custos locais se elevem. Essa elevação de custo do comércio bilateral, decorrente de altos custos no mercado de destino que geram preços locais mais altos, consiste no fator de repulsão do fluxo de comércio. Essa é a essência do modelo desenvolvido por Jonathan Eaton e Samuel Kortum (2002).

\subsection{A Abordagem Cepalina e o Modelo Eaton-Kortum}

A despeito das enormes divergências entre as duas teorias, algumas proposições analíticas evocadas pela teoria estruturalista e pelo modelo considerado apresentam similitudes entre si, uma vez que apontam para alguns insights importantes na devida compreensão do desempenho qualitativo do comércio bi ou multilateral entre economias estruturalmente distintas. Em ambas, a questão do preço (e não somente o quantum) das exportações e das importações emerge como um parâmetro capaz de revelar o padrão e os benefícios das trocas realizadas por uma dada economia.

No caso da teoria cepalina, os preços dos produtos exportados e importados para os países mais pobres (periferia), via de regra, estão associados à deterioração dos termos de troca, ou seja, à tendência histórica dos países menos desenvolvidos e produtores de produtos de menor valor agregado assumir posições de desvantagem nas relações comerciais. No modelo Eaton-Kortum, existe uma nítida admissão dos diferenciais de benefícios entre as nações ao inserirem-se no âmbito do comércio internacional, ainda que se considere a simples realização das trocas entre países como um processo gerador de benefícios líquidos.

Outro fator de tangência entre as análises consiste na importância atribuída à técnica como base explicativa para a compreensão da existência de heterogeneidades na capacidade competitiva entre regiões distintas. No argumento cepalino, com a introdução de técnicas produtivas mais eficazes, a maior produtividade constituiria um fator preponderante, ao permitir maiores montantes de poupança para o financiamento de novos investimentos; a propósito, a própria deterioração dos termos de troca seria uma implicação direta da transferência dos frutos do pro- 
gresso técnico da periferia para os centros do capitalismo mundial. Já no modelo gravitacional em questão, também se consideram as heterogeneidades tecnológicas, enquanto expressões inalienáveis das vantagens comparativas demonstradas pelos países.

A relação entre a produtividade e o progresso técnico nessas abordagens é de uma magnitude tal que aumentos na produtividade pressupõem o progresso técnico. Na abordagem cepalina, a elevação da produtividade exige inversões em máquinas, equipamentos e técnicas mais eficientes que potencializem a produtividade do trabalho. No modelo Eaton-Kortum, a produtividade também está relacionada com o nível da técnica ou tecnologia alcançada, sendo discrepantes entre as diferentes regiões - não obstante, se abstém de esboçar proposições de ordem mais crítica acerca dos diferentes padrões de inserção dos países no âmbito do comércio internacional, como será o caso dos economistas latino-americanos.

Outra questão fundamental é que as barreiras comerciais não apresentam uma importância trivial para as formulações supracitadas, uma vez que possuem a capacidade de engendrar alterações no quadro de retornos advindos do comércio. Os cepalinos, com o intuito de promoverem a industrialização dos países da América Latina, identificam nesse subterfúgio um potencial para estimular e proteger a indústria nacional em desenvolvimento. Tal acepção adquire uma interpretação ligeiramente distinta nos trabalhos de Eaton e Kortum (2002) e nos demais modelos gravitacionais ao defenderem que o comércio internacional, em menor ou maior medida, tende a causar efeitos positivos para todos os seus participantes, de modo que qualquer tipo de barreira locacional e comercial dificulta e reduz globalmente os benefícios do livre-comércio, mesmo que em magnitude distinta para cada economia de acordo com a intensidade e a natureza dessas mesmas barreiras.

Ademais, o setor de bens intermediários ocupa um lugar de destaque nas duas abordagens, no sentido de que, na teoria cepalina, esse segmento estaria no âmbito da segunda etapa do processo de industrialização por intermédio da substituição das importações, de modo que a produção interna de insumos e bens intermediários de maior valor agregado seria uma condição sine qua non para que o esforço de internalização dos elementos dinâmicos das economias latino-americanas lograsse êxito. Eaton e Kortum (2002), em seu modelo gravitacional de caráter estrutural, também ressaltam a importância dos setores de insumos nas trocas internacionais (precipuamente, aqueles de maior densidade tecnológica) e reiteram que o comércio internacional possibilita a circulação desse tipo de bem a preços inferiores àqueles que seriam verificados em um regime de autarquia. 


\section{Método}

Como o interesse do presente estudo recai sobre a investigação das exportações brasileiras de bens intermediários, de capital, duráveis e não duráveis, tendo por base o modelo Eaton-Kortum (EK), será empregado quatro equações semelhantes em termos de variáveis independentes. Ressalta-se que as informações referentes às exportações brasileiras no período de 1980 a 2015 foram extraídas da base de dados do Ipeadata, bem como os dados atinentes ao PIB de cada país (Holanda, Alemanha, França, Estados Unidos, Japão e China). A taxa de câmbio real efetiva foi obtida no banco de dados do Banco Mundial (2015). A partir dessas informações, as equações gravitacionais podem ser especificadas da seguinte maneira:

a) modelo 1 de bens intermediários:

$\ln \left(\mathrm{EXP}_{-} \mathrm{BI}_{\mathrm{it}}\right)=\alpha_{0}+\alpha_{\mathrm{i}}+\beta_{1} \ln \left(\mathrm{PIB}_{\mathrm{jt}}\right)+\beta_{2} \ln \left(\mathrm{PIB}_{-} \mathrm{BR}_{\mathrm{it}}\right)+\beta_{3} \ln \left(\mathrm{CAMB}_{\mathrm{ijt}}\right)+\delta$ crise $+\beta_{4} \ln \left(\mathrm{DIST}_{\mathrm{ij}}\right)+\varepsilon_{\mathrm{it}}$

b) modelo 2 de bens de capital:

$\ln \left(\mathrm{EXP}_{\text {BKit }}\right)=\alpha_{0}+\alpha_{\mathrm{i}}+\beta_{1} \ln \left(\mathrm{PIB}_{\mathrm{jj}}\right)+\beta_{2} \ln \left(\mathrm{PIB}_{\mathrm{BRit}}\right)+\beta_{3} \ln \left(\mathrm{CAMB}_{\mathrm{jij}}\right)+\delta$ crise $+\beta_{4} \ln \left(\operatorname{DIST}_{\mathrm{ij}}\right)+\varepsilon_{\mathrm{it}}$

c) modelo 3 de bens duráveis:

$\ln \left(\mathrm{EXP}_{-} \mathrm{BD}_{\mathrm{it}}\right)=\alpha_{0}+\alpha_{\mathrm{i}}+\beta_{1} \ln \left(\mathrm{PIB}_{\mathrm{jt}}\right)+\beta_{2} \ln \left(\mathrm{PIB}_{-} \mathrm{BR}_{\mathrm{it}}\right)+\beta_{3} \ln \left(\mathrm{CAMB}_{\mathrm{ijt}}\right)+\delta$ crise

$+\beta_{4} \ln \left(\mathrm{DIST}_{\mathrm{ij}}\right)+\varepsilon_{\mathrm{it}}$

d) modelo 4 de bens não duráveis:

$\ln \left(\mathrm{EXP}_{-} \mathrm{BND}_{\mathrm{it}}\right)=\alpha_{0}+\alpha_{\mathrm{i}}+\beta_{1} \ln \left(\mathrm{PIB}_{\mathrm{j}}\right)+\beta_{2} \ln \left(\mathrm{PIB}_{-} \mathrm{BR}_{\mathrm{it}}\right)+\beta_{3} \ln \left(\mathrm{CAMB}_{\mathrm{ijt}}\right)+\delta$ crise $+\beta_{4} \ln \left(\mathrm{DIST}_{\mathrm{ij}}\right)+\varepsilon_{\mathrm{it}}$

Nesses casos, têm-se as seguintes variáveis dependentes: EXP_BI: exportações totais brasileiras de bens intermediários; EXP_BK: exportações totais brasileiras de bens de capital; EXP_BD: exportações totais brasileiras de bens de consumo duráveis; e EXP_BND: exportações totais brasileiras de bens de consumo não duráveis, em logaritmo natural. Como variáveis explanatórias, têm-se: $\ln \left(\mathrm{PIB}_{\mathrm{j} t}\right)$, que representa o logaritmo do PIB do país j no ano $t$; $\ln \left(\mathrm{PIB}_{-} \mathrm{BR}_{\mathrm{it}}\right.$ ) é o logaritmo do PIB 
do Brasil, que no caso é indicado pelo subscrito i no período $t$; e $\ln \left(\mathrm{CAMB}_{\mathrm{ijt}}\right)$ é o logaritmo da taxa real de câmbio real efetiva do Brasil em relação ${ }^{2}$ ao país j no ano $t$.

A variável crise é uma dummy com o objetivo de captar o efeito da crise financeira internacional de 2008 nas exportações brasileiras. Por fim, $\ln \left(\right.$ DIST $_{\mathrm{ij}}$ ) é o logaritmo da distância entre a capital brasileira e das demais capitais de cada país. Por fim, os parâmetros $\alpha_{0}, \alpha_{\mathrm{i}}$ e $\varepsilon_{\mathrm{it}}$ representam, respectivamente, o intercepto dos modelos, o termo idiossincrático pertinente a cada indivíduo no painel, que é constante no modelo, e o termo de erro aleatório do modelo.

Conforme os pressupostos do modelo gravitacional ${ }^{3}$, o tamanho da economia em termos de produto interno, tanto da emissora quanto da receptora, tende a estimular as interações comerciais e, por conseguinte, os fluxos das exportações. Portanto, conjectura-se que o sinal esperado para o PIB das economias em relação às exportações seja positivo. Por sua vez, espera-se que maiores distâncias engendrem redução no fluxo de vendas. Ademais, os termos de troca entre os países, expressos na taxa de câmbio, denotam a importância de preços atraentes para que o país exportador expanda suas vendas, sugerindo que uma depreciação cambial seja um fator capaz de elevar os fluxos de comércio externo.

O presente trabalho faz uso da modelagem com dados em painel, que consiste em uma técnica que combina dados de corte transversal com séries temporais. Sendo assim, com essa metodologia é possível levar em consideração as características idiossincráticas pertinentes aos fatores socioeconômicos, culturais, institucionais e legislativas. O fato é que a utilização da modelagem com dados em painel fornece ganhos de graus de liberdade, além de permitir melhor tratamento da heterogeneidade, o que não seria realizado caso apenas fosse aplicado um método de séries temporais ou de cross-section (BALTAGI, 2005).

Além disso, quando se utiliza um modelo em painel, existe a possibilidade de construção e de tratamento de modelos comportamentais, que em geral são inviabilizados quando empregados somente dados de cortes transversais empilhados (GREENE, 2003). Cabe ressaltar que, dentro da metodologia em painel, estão presentes os modelos pooled, efeitos fixos (EF) e efeitos aleatórios (EA). O pooled é uma técnica que consiste em empilhar os dados temporais e cross-section. A estimação $\mathrm{EF}$ trabalha com as heterogeneidades individuais de cada grupo dos países e são captadas por um termo constante para cada indivíduo, como, por exemplo, o tratamento de um setor da economia ou determinada região. Cabe ressaltar que,

2 Para construção dessa variável, dividiu-se o valor da taxa real de câmbio de cada país $i$ para o dólar pela taxa real de câmbio brasileira para o dólar.

3 O modelo gravitacional foi sugerido por Jan Tinbergen (1962) em seu livro Shaping the world economy: suggesteion for an international economic policy (1962). O nome do modelo alude à Lei da Gravitação Universal de Isaac Newton, que entende o volume de comércio como positivamente dependente do "tamanho" do país (PIB, PNB, etc.) e inversamente dependente da distância entre os mesmos. 
ao se trabalhar com modelos EF, não se consegue obter estimativas de algumas características invariantes no tempo (ex: etnia e gênero).

Caso a heterogeneidade não seja significativa, o melhor modelo será o EA. Quando o modelo EA é utilizado, assume-se a ausência de correlação perfeita entre as variáveis explanatórias. Para a seleção do tipo de modelo que melhor se ajusta a esta investigação, são utilizados testes estatísticos e econométricos, tais como Hausman, Breusch-Pagan e Chow. Por sua vez, para a análise acerca dos problemas de heterocedasticidade e autocorrelação, recorre-se, respectivamente, ao testes de Wald e de Wooldridge.

No teste Chow, a hipótese nula é que não há heterogeneidade, de modo que o modelo pode ser estimado via pooled. A hipótese alternativa é que as heterogeneidades estão presentes no modelo, sendo necessário recorrer ao método de estimação EF. Caso a heterogeneidade não seja significativa, testa-se a técnica pooled contra EA, mediante o teste Breusch-Pagan, no qual a hipótese nula do modelo é de que a variância no termo estocástico é igual a zero. Caso não se conste evidência estatística para a rejeição dessa hipótese, o melhor modelo é o pooled. Todavia, caso seja rejeitada a hipótese nula, a hipótese alternativa de EA torna-se a mais indicada.

Para decidir entre EA e EF será utilizado o teste de Hausman, cujas hipóteses são baseadas nas correlações entre as variáveis explanatórias e a heterogeneidade não observada. Ou seja, a hipótese nula do teste de Hausman é EA, que assume ausência de correlação entre as variáveis independentes, sendo o EF a hipótese alternativa que, por sua vez, assume correlação entre os regressores e o efeito não observado. Caso não exista essa correlação, o melhor modelo a ser estimado é o EA.

Com relação ao problema de heterocedasticidade, utiliza-se o teste de Wald, o qual apresenta como hipótese nula a homocedasticidade nos resíduos do modelo EF. Esse problema causa dificuldades para se analisar a significância dos parâmetros estimados e modificações quanto aos sinais esperados para o caso da correlação serial. Com vistas a superar essa limitação, utiliza-se o teste de Wooldridge, o qual tem por hipótese nula a não autocorrelação nos resíduos. Por fim, para se testar se existe problema de dependência dos cross-section, ou seja, correlação contemporânea, aplica-se o teste proposto por Pesaran (2004). Com fins de superar os problemas de estimação, conforme ressaltado anteriormente, emprega-se o estimador EF proposto por Driscoll-Kraay (1998). Esse estimador é o mais indicado ${ }^{4}$ porque trata, simultaneamente, os problemas da heterocedasticidade, da correlação contemporânea e da correlação serial.

$4 \quad$ Para mais detalhes e motivações do uso dessa metodologia em vez da metodologia de Panel-Corrected Standard Errors (PCSE) ou Feasible Generalized Least Squares (FGLS), pode ser encontrada em Hoechle (2007). 


\section{Análise dos Resultados}

Uma vez realizado o cotejo entre a abordagem cepalina e o modelo EK, bem como apresentado os elementos metodológicos centrais que sustentam esse último instrumental e sua devida mobilização e articulação no escopo do presente trabalho, segue abaixo a discussão acerca dos principais resultados referentes à investigação empírica das aquisições nacionais de bens intermediários, de capital, duráveis e não duráveis para o período circunscrito entre 1980 a 2015.

\subsection{Testes Preliminares}

A Tabela 1 reporta aos resultados atinentes à realização dos testes Breusch-Pagan, Hausman e Chow, com o intuito de selecionar os modelos de estimação mais ajustáveis para os quatro casos investigados. A aplicação desses testes indicou que o modelo do tipo EF é o mais eficiente em termos estatísticos para o devido tratamento e análise das características do objeto perscrutado. Isso porque, em todos os modelos em questão, o teste Hausman, ao avaliar a eficiência do modelo EA em relação ao modelo $\mathrm{EF}$, resultou em um $p$-valor aproximadamente igual a 0.00 para todos os modelos a serem estimados, o que, ao nível de significância de $1 \%$, sugere a rejeição da hipótese nula de que há uma superioridade em termos de eficiência do modelo EA em relação ao modelo EF. As estatísticas obtidas na realização do teste Hausman e Chow indicaram que a estimação via o modelo EF é mais indicada do que via pooled para todas as equações gravitacionais. Em função disso, serão apresentados e interpretados somente os resultados obtidos pela estimação dos modelos gravitacionais com EF.

Tabela 1 - Estatísticas dos testes de seleção do modelo de dados em painel

\begin{tabular}{lcc}
\hline \multicolumn{1}{c}{ Modelo } & Hausman & Chow \\
\hline Modelo 1: bens intermediários & 0.00 & 0.04 \\
Modelo 2: bens de capital & 0.00 & 0.03 \\
Modelo 3: bens de consumo duráveis & 0.00 & 0.00 \\
Modelo 4: bens de consumo não duráveis & 0.00 & 0.00 \\
\hline
\end{tabular}

Fonte: Elaboração própria.

Nota: $p$-valor para ambos os testes.

Por sua vez, a Tabela 2 apresenta as estatísticas do $p$-valor calculado para o teste Wooldridge e Wald. No que se refere ao primeiro teste, é possível observar estatísticas encontradas que, ao nível de significância de 1\%, indicam a existência de problemas de correlação serial para todos os modelos. Por outro lado, o teste 
Wald indicou que não há evidência estatística para rejeição da hipótese de homocedasticidade em todos os modelos estimados.

Tabela 2 - Estatísticas dos testes de Wooldridge e de Wald

\begin{tabular}{lccc}
\hline \multicolumn{1}{c}{ Modelo } & Wooldridge & Wald & Pesaran \\
\hline Modelo 1: bens intermediários & 0,00 & 0,99 & 0,00 \\
Modelo 2: bens de capital & 0,00 & 0,94 & 0,00 \\
$\begin{array}{l}\text { Modelo 3: bens de consumo } \\
\text { duráveis }\end{array}$ & 0,00 & 0,97 & 0,00 \\
$\begin{array}{l}\text { Modelo 4: bens de consumo não } \\
\text { duráveis }\end{array}$ & 0,00 & 0,77 & 0,00 \\
\hline
\end{tabular}

Fonte: Elaboração própria.

Nota: A estatística do teste é apresentada em termos de $p$-valor.

Ao se analisar as estatísticas do teste de Pesaran (2004), verifica-se que, ao nível e significância de 1\%, existem problemas de correlação contemporânea em todos os modelos. Conforme verificado, estão presentes nos modelos o problema de correlação serial e correlação contemporânea. O recurso empregado para a estimação e superação desses problemas baseia-se na metodologia proposta por Driscoll-Kraay (1998).

\subsection{Estimação e Interpretação do Modelo}

Conforme a tabela do Apêndice $\mathrm{A}$, que reporta às estatísticas das variáveis utilizadas no modelo empírico do presente estudo, os Estados Unidos correspondem em média à nação que possui o maior PIB, seguido da China, Japão, Alemanha, França e Holanda, respectivamente. Ressalva-se que como o modelo gravitacional se utiliza de uma variável que é invariante no tempo, mesmo assim a estimação é possível via efeitos fixos Driscoll-Kraay (1998), porém o próprio método exclui a constante do modelo $\left(\alpha_{0}\right)$ para evitar problemas de estimação.

Verifica-se que, em média, o Brasil exporta mais produtos intermediários e bens não duráveis, seguido pelos bens de capital e dos bens de consumo duráveis. Também é possível verificar que os bens de capital foram os produtos que apresentaram a maior taxa de crescimento anual, com aproximadamente $9.13 \%$, seguido dos bens de consumo intermediários, com 7.97\%, dos bens de consumo não duráveis, com $6.69 \%$, e, por fim, dos bens de consumo duráveis, sendo de $6.01 \%$.

Na Tabela 3 estão explicitados todos os resultados pertinentes à estimação dos modelos para as exportações por grau de elaboração. Observou-se significância estatística para o PIB dos países (i) em todos os modelos estimados com o sinal esperado, em especial para os bens de consumo não duráveis, para o qual esse co- 
eficiente se mostrou importante no sentido de que o aumento de no PIB dos países (i) considerados eleva as exportações brasileiras desse tipo de venda em , porém, nas demais exportações por grau de elaboração, esse coeficiente foi em média

Tabela 3 Resultados econométricos do modelo gravitacional

\begin{tabular}{|c|c|c|c|c|}
\hline & $\begin{array}{l}\text { Bens de con- } \\
\text { sumo } \\
\text { intermediário } \\
(1)\end{array}$ & $\begin{array}{l}\text { Bens de } \\
\text { capital } \\
\text { (2) }\end{array}$ & $\begin{array}{l}\text { Bens de } \\
\text { consumo } \\
\text { duráveis } \\
\text { (3) }\end{array}$ & $\begin{array}{l}\text { Bens de con- } \\
\text { sumo não } \\
\text { duráveis } \\
\text { (4) }\end{array}$ \\
\hline \multirow[t]{2}{*}{$\ln \left(\mathrm{PIB}_{\mathrm{jt}}\right)$} & $0.220 *$ & $0.221^{*}$ & $0.324 * *$ & $0.242 * *$ \\
\hline & $(0.089)$ & (0.113) & $(0.102)$ & $(0.080)$ \\
\hline \multirow[t]{2}{*}{$\ln \left(\mathrm{PIB}_{-} \mathrm{BR}_{\mathrm{it}}\right)$} & $2.355 * * *$ & $2.88^{* * *}$ & $1.529 * * *$ & $1.858 * * *$ \\
\hline & $(0.350)$ & $(0.295)$ & $(0.269)$ & $(0.280)$ \\
\hline \multirow{2}{*}{$\ln \left(\mathrm{CAMB}_{\mathrm{ijt}}\right)$} & 0.023 & 0.220 & $0.400 * *$ & 0.181 \\
\hline & $(0.188)$ & $(0.186)$ & $(0.155)$ & $(0.166)$ \\
\hline \multirow[t]{2}{*}{ crise } & $0.244^{*}$ & 0.250 & $0.2633^{*}$ & $0.368 * *$ \\
\hline & $(0.118)$ & $(0.150)$ & $(0.127)$ & $(0.102)$ \\
\hline \multirow{2}{*}{$\ln \left(\mathrm{DIST}_{\mathrm{ij}}\right)$} & $-1.883 * * *$ & $-2.673 * * *$ & $-1.682 * * *$ & $-1.610 * * *$ \\
\hline & $(0.235)$ & $(0.280)$ & $(0.231)$ & $(0.208)$ \\
\hline $\mathrm{R}^{2}$ & 0.8715 & 0.8944 & 0.7902 & 0.8519 \\
\hline Prob $>F$ & 0.000 & 0.000 & 0.000 & 0.000 \\
\hline
\end{tabular}

Fonte: Elaboração própria a partir das estimações da pesquisa.

Nota: Erro padrão entre parênteses; ** ${ }^{*}$ significativo a $1 \%,{ }^{* *}$ significativo a $5 \%$ e * significativo a $10 \%$.

No que diz respeito ao PIB do Brasil, verifica-se significância estatística para todos os modelos, evidenciando-se o impacto positivo do crescimento econômico interno sobre as exportações. Mais especificamente, constata-se um impacto maior do aumento no PIB sobre as exportações brasileiras de bens intermediários e de capital do que os bens de consumo duráveis e não duráveis.

A taxa de câmbio também se mostrou estatisticamente significativa somente para o modelo 3. Ou seja, uma depreciação cambial da moeda brasileira em relação à moeda da economia de destino corrobora o aumento apenas das exportações brasileiras de bens duráveis. Mais especificamente, o sinal positivo indica que o aumento de $1 \%$ da taxa de câmbio da moeda local, perante a moeda dos demais países, eleva as exportações de bens duráveis em aproximadamente .

Conforme esperado, o coeficiente relacionado à distância entre os países se mostrou negativo e altamente significativo a para todos os modelos. Esse resultado comprova a proposição de que os custos de transportes aumentam com a distân- 
cia entre as economias. Por fim, cabe ressaltar a significância estatística da variável dummy que visa controlar o efeito da crise financeira internacional de 2008 sobre as exportações brasileiras. Com base nas estimativas apresentadas, verifica-se que no caso brasileiro, exceto para os bens de capital, a crise teve impacto positivo. Porém, esse resultado deve ser interpretado com cautela, devido à baixa significância estatística em todos os modelos. Apesar da não significância de alguns parâmetros, o teste $\mathrm{F}$ e o coeficiente de determinação indicaram que os modelos estão adequadamente ajustados.

$\mathrm{Na}$ teoria cepalina, os preços relativos expressam a própria discrepância estrutural entre o centro e a periferia no âmbito do comércio internacional, uma vez que representam os termos de troca sob os quais as economias estabelecem seus intercâmbios comerciais, que podem ser favoráveis ou desfavoráveis ao processo de desenvolvimento econômico das economias periféricas. É possível inferir que, em relação aos termos de troca, uma interpretação à luz das proposições cepalinas se daria no sentido de confirmar a plausibilidade da preocupação dos seus teóricos quanto às características discrepantes entre as economias, apenas para os bens de consumo duráveis, dado a capacidade da taxa de câmbio explicar essas exportações em específico.

Entretanto, foi possível verificar que, para os demais setores, os preços relativos não foram significativos na explicação das exportações brasileiras. Portanto, uma interpretação à luz do arcabouço cepalino desse resultado evidencia que, com exceção dos bens de consumo duráveis, as vendas brasileiras não respondem substancialmente aos estímulos de preços relativos, e que eventuais variações cambiais apresentariam pouca efetividade no fomento nas exportações dos bens de capital, de intermediários e de não duráveis.

Os teóricos cepalinos apontaram para a deficiência histórica brasileira em competir nos setores que exigem maior densidade de capital e nível tecnológico, a exemplo dos setores de bens de produção. Na ausência de ganhos de produtividade, não raras vezes, a estratégia governamental adotada consistiu em buscar ganhos externos com base em medidas cambiais espúrias, a exemplo de desvalorizações induzidas da moeda nacional face às estrangeiras, em vez de promover as reformas estruturais necessárias para o aumento da produtividade em setores mais dinâmicos, bem como o fortalecimento da competitividade do Brasil no comércio internacional.

Também é possível inferir que o tamanho da economia brasileira e das economias demandantes das exportações nacionais é fundamental na explicação do fluxo de vendas externas do Brasil. Portanto, os argumentos cepalinos em prol do crescimento e da diferenciação produtiva na periferia, como estratégia de qualificação da inserção dessas economias no comércio internacional, torna-se empiricamente justificável à luz dos resultados encontrados. Esse resultado também 
demonstra grande convergência para o modelo gravitacional em questão, dado a sua proposição de que um maior tamanho das economias estimula o fluxo comercial entre aquelas mais próximas.

Ademais, as barreiras comerciais prestam uma importância longe de ser trivial na teoria cepalina e no modelo EK, ainda que com interpretações substancialmente distintas. O fato é que tal preocupação está expressa no fator de repulsão dos modelos gravitacionais baseados nos custos de transportes, de modo a comprovar que as despesas implicadas nas barreiras comerciais (naturais ou artificiais) possuem expressiva influência na determinação do comportamento da maior parte das exportações distinguidas por graus de elaboração. Para o modelo EK, tais barreiras tendem a impactar negativamente as exportações, reproduzindo a interpretação de que a distância territorial se apresenta tradicionalmente nos modelos gravitacionais. Nos resultados obtidos, a importância da distância nas exportações nacionais se confirmou para todas as exportações por grau de elaboração, com elevado grau de significância e com o sinal esperado.

Para os cepalinos, a interpretação dessa inferência não poderia ser feita de maneira tão mecânica e ligeira, uma vez que as barreiras comerciais (com destaque para as geradas via tarifa) podem exercer um papel importante e estratégico para a proteção da indústria e dos interesses nacionais, a exemplo dos casos em que o Estado objetiva criar e fomentar uma indústria ainda não existente, ou ainda não devidamente desenvolvida internamente para competir com seus congêneres dos países centrais. Embora não tenha sido uma preocupação explícita dos teóricos cepalinos estabelecerem proposições acerca da relação existente entre distâncias e o fluxo de comércio internacional, as barreiras comerciais não eram interpretadas como inerentemente desfavoráveis ao processo de desenvolvimento de uma economia periférica desde que fossem alinhadas aos interesses nacionais. Nesse contexto, barreiras naturais e artificiais poderiam eventualmente criar novas possibilidades de comércio e de inserção em mercados que dificilmente poderiam ser viabilizadas na ausência de estrangulamentos externos, barreiras geográficas, tarifas, entre outros.

Por fim, com alguma cautela é possível observar que a dummy que cobre os efeitos da crise internacional de 2008 sobre as exportações brasileiras revela que, exceto para o setor de bens de capital, as vendas nacionais foram beneficiadas com a crise financeira internacional. Tal inferência merece maior investigação e aprofundamento futuro. Uma possível explicação talvez resida no fortalecimento da parceria comercial empreendida pelo Brasil com alguns países nesse período um exemplo foi o caso da China, para o qual as vendas apresentaram uma tendência de elevação entre 2008 e 2011, sofrendo revés apenas após esse interregno. Além disso, o fato do Brasil ter experimentado menor declínio na dinâmica de sua economia, no período imediatamente posterior à crise mundial, e ter se recupera- 
do com relativa rapidez pode ter fortalecido a posição e a credibilidade do país no âmbito do comércio internacional no período considerado.

\section{Considerações Finais}

No debate teórico e comparativo entre a abordagem consagrada pelos intelectuais estruturalista-cepalinos na América Latina e o promissor modelo gravitacional estrutural formulado por Eaton e Kortum, é possível chegar a certas inferências mais conclusivas e claras acerca das tangências e divergências teóricas existentes entre essas abordagens. Nas duas teorias, o preço relativo das exportações emerge como um parâmetro que expressa em alguma medida o padrão e a qualidade das trocas realizadas entre as economias, dado a atenção teórica dispensada pela teoria estruturalista-cepalina na investigação do perfil das trocas historicamente estabelecidas entre diferentes economias, bem como pela capacidade do modelo EK de efetuar análises estruturais mediante estudos por setores ou graus de elaboração, a exemplo daqueles empregados no presente trabalho.

As duas abordagens também apontam para as diferenças técnicas entre as regiões como base explicativa para a compreensão das discrepâncias em termos de capacidade competitiva entre as economias. Na primeira, a deterioração dos termos de troca seria uma implicação direta da transferência dos frutos do progresso técnico da periferia para os centros do capitalismo mundial. No modelo EK, as heterogeneidades tecnológicas são incorporadas como expressões inalienáveis das vantagens comparativas demonstradas pelos países.

As barreiras comerciais também exercem papel preponderante nas duas proposições. Para os cepalinos, podem até mesmo cumprir papel fundamental na estratégia de desenvolvimento e na promoção da indústria nacional. Uma visão diametralmente oposta é fornecida pelos modelos gravitacionais em geral, nos quais as barreiras (naturais ou artificiais) oneram as transações e implicam deterioração dos fluxos comerciais.

$\mathrm{Na}$ análise das exportações brasileiras entre 1980 e 2015 por graus de elaboração a partir do modelo EK e daqueles argumentos cepalinos que o tangenciam, constataram-se certas inferências interessantes que exigirão novos trabalhos posteriores para aprofundá-las. A primeira é a considerável capacidade dos produtos de países como Estados Unidos, China, Alemanha, França, Holanda e Japão de explicarem as exportações brasileiras. Os resultados parecem sugerir que os preços relativos não desempenham um papel determinante nas exportações nacionais, com exceção das vendas externas dos bens duráveis. Entretanto, as barreiras comerciais exercem um papel de grande centralidade na explicação dessas exportações, embora as abordagens consideradas apresentem interpretações distintas entre si para esse aspecto. O fato é que as exportações brasileiras estão mais as- 
sociadas aos fatores explicativos vinculados às noções gravitacionais de tamanho e barreiras comerciais em termos de distância do que com as variações cambiais propriamente ditas.

Com base nos resultados obtidos evidencia-se que, em termos de política econômica, reduções na taxa de câmbio, com vistas a engendrar diferenciais nas vendas externas brasileiras, teriam pouca efetividade em fomentar as exportações nacionais e que o crescimento da economia nacional e dos parceiros comerciais tende a fortalecer ainda mais as vendas externas. Por outro lado, a importância das barreiras comerciais observadas nos resultados encontrados engendra certa ambiguidade quanto à orientação de cada corrente no que se refere à política econômica sugerida. Para os estruturalistas, as barreiras podem ser coordenadas e submetidas aos interesses nacionais com o intento de estimular certos setores, ou mesmo, a produção de determinados bens estratégicos. Contudo, no modelo EK esse artifício seria interpretado como um entrave substancial para o crescimento nacional, de modo que deveria ser completamente abandonado caso o objetivo fosse aumentar o nível de competitividade das vendas nacionais no mercado externo.

\section{Referências}

ALVAREZ, F.; LUCAS JUNIOR, R. E. General equilibrium analysis of the Eaton-Kortum model of international trade. Journal of Monetary Economics, n. 54, p. 1726-1768, 2007.

BALDWIN, R.; HARRIGAN, J. Zeros, quality and space: trade theory and trade evidence. American Economic Journal: Microeconomics, v. 3, n. 2, p. 60-88, May 2011.

BALTAGI, B. H. Econometric analysis of panel data. 3. ed. Chichester: John Wiley $\mathcal{Z}$ Sons, 2005.

COMISSÃO ECONÔMICA PARA AMÉRICA LATINA E CARIBE. Estudo econômico da América Latina. In: BIELSTHOWSKY, R. (Org.). Cinqüenta anos de pensamento da Cepal. Tradução de Vera Ribeiro. Rio de Janeiro: Record, 2000. p. 137-178. v. 1.

DOSI, G. Technological paradigms and technological trajectories. Research Policy, v. 11, n. 3, p. 147-162, June 1982.

DRISCOLL, J. C., KRAAY, A. C. Consistent covariance matrix estimation with spatially dependent panel data. Review of Economics and Statistics, v. 80, p. 549-560, 1998.

EATON, J.; KORTUM, S. Technology, geography and trade. Econometria, v. 70, n. 5, p. 17411779, Sept. 2002.

FREEMAN, C; PEREZ, C. Structural crises of adjustment: business cycles and investiment behaviour. In: DOSI, G; FREEMAN, C; NELSON, R. (Eds.). Technical change and economic theory. London: Frances Pinter, 1988. p. 38-66. 
FURTADO, Celso. O subdesenvolvimento revisitado. Economia e Sociedade, Campinas, v. 1, n. 1, p. 5-19, 1992.

GREENE, W. H. Econometric analysis. 5. ed. Upper Saddle River, NJ, USA: Prentice Hall, 2003.

GUJARATI, D. N.; PORTER, D. C. Econometria básica. Porto Alegre: AMGH, 2011.

HOECHLE, D. Robust standard errors for panel regressions with cross-sectional dependence. Stata Journal, v. 7, n. 3, p. 281-312, 2007.

OLIVEIRA, F. H. P.; SANTOS, U. P. As três fases da teoria cepalina: uma análise de suas principais contribuições ao pensamento econômico latino americano. Análises, Porto Alegre, v. 19, n. 2, p. 4-17, jul./dez. 2008.

PESARAN, M. H. General diagnostic tests for cross section dependence in panels. Cambridge: University of Cambridge, 2004. (Cambridge Working Papers in Economics, nº 0435).

PICO BONILLA, C. M. Comercio de manufacturas en América Latina: una revisión de la experiencia de liberalización en los noventa desde la teoría ricardiana. Bogotá, Colombia, 2011. Disponível em: <http://repository.urosario.edu.co/handle/10336/2579>. Acesso em: 22 nov. 2015.

PORCILE, G.; ESTEVES, L. A.; SCATOLIN, F. D. Tecnologia e desenvolvimento econômico. In: PELAEZ, V.; SZMRECSÁNYI, T. (Org.). Economia da inovação tecnológica. São Paulo: Hucitec, 2006. p.30-58.

PREBISCH, R. O desenvolvimento econômico da América Latina e alguns de seus principais problemas. In: BIELSCHOWSKY, R. (Org.). Cinqüenta anos de pensamento na Cepal. Rio de Janeiro: Record, 2000. p. 69-137. v. 1.

SCHUMPETER, J. A. A teoria do desenvolvimento econômico. São Paulo: Abril Cultural, 1982. (Série Os Economistas).

TAVARES, M. C. Da substituição de importações ao capitalismo financeiro: ensaios sobre a economia brasileira. Rio de Janeiro: Zahar, 1975.

TINBERGEN, J. Shaping the world economy suggestions for an international economic policy. New York: Twentieh Century Fund, 1962.

WORLD BANK. The World Bank Open Data. Disponível em: < https://data.worldbank. org/>. Acesso em 06 jun. 2015. 
Apêndice A - Estatísticas descritivas

\begin{tabular}{|c|c|c|c|}
\hline País & PIB * & Câmbio & Distância \\
\hline USA & $\$ 9,476.38$ & 1.4922 & $6458.16 \mathrm{~km}$ \\
\hline $\mathrm{CHN}$ & $\$ 5,260.20$ & 1.5703 & $16941.74 \mathrm{~km}$ \\
\hline JPN & $\$ 3,023.29$ & 1.3064 & $17361.86 \mathrm{~km}$ \\
\hline DEU & $\$ 2,131.24$ & 1.3710 & $9682.34 \mathrm{~km}$ \\
\hline FRA & $\$ 1,492.68$ & 1.3480 & $8807.49 \mathrm{~km}$ \\
\hline NLD & $\$ 454.10$ & 1.2959 & $9182.12 \mathrm{~km}$ \\
\hline Intermediários* & $\$ 58174.46$ & \multirow{4}{*}{ 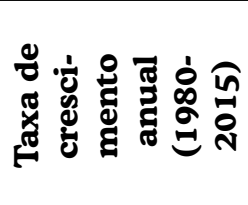 } & $7.97 \%$ \\
\hline Duráveis* & $\$ 3277.05$ & & $6.01 \%$ \\
\hline Não duráveis * & $\$ 13072.62$ & & $6.69 \%$ \\
\hline Bens de capital* & $\$ 7800.71$ & & $9.13 \%$ \\
\hline
\end{tabular}

Fonte: Elaboração própria a partir de estimações da pesquisa.

Nota: * Milhões de dólares

Recebido em: 17/02/2016. Aceito em: 06/09/2017. 